\title{
Update on lasers in urology 2015
}

\author{
Thomas R. W. Herrmann ${ }^{1}$ Thorsten Bach ${ }^{2}$
}

Published online: 17 March 2015

(C) Springer-Verlag Berlin Heidelberg 2015

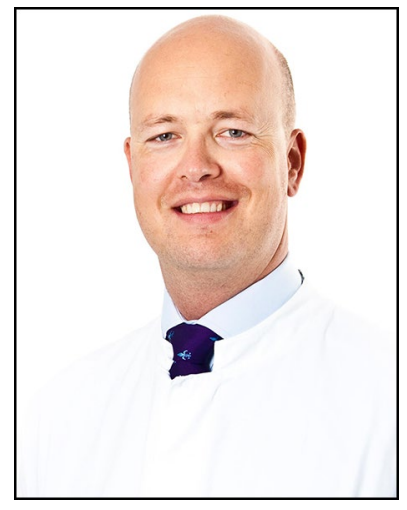

Thomas R. W. Herrmann

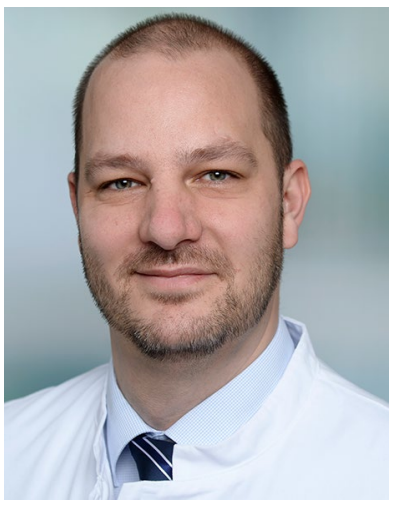

Thorsten Bach
Lasers have become a major workhorse in daily urology. Stone fragmentation, using the Ho:YAG laser, is widely accepted as the standard of intracorporal lithotripsy in ureteroscopy. Besides these well-known applications, laser treatment in surgery of LUTS due to benign prostatic obstruction has become more and more prevalent in the daily routine. Different techniques, varying from vaporization over resection to enucleation, have been described and introduced into clinical utilization. And now, laser enucleation even expands to the en-bloc removal of bladder

Thomas R. W. Herrmann

Herrmann.Thomas@mh-hannover.de

1 Division of Endourology and Laparoscopy, Hanover Medical School (MHH), Dept. of Urology and Urological Oncology, Carl Neuberg Str. 1, Hanover 30625, Germany

2 Asklepios Clinic Harburg, Dept. of Urology, Eißendorfer Pferdeweg 52, Hamburg 21075, Germany tumours and partial nephrectomy, opening the field for even more techniques.

This special edition of the World Journal of Urology is the logical consequence and update on previously published special issues on Lasers in Urology, as seen in 2007 [1] and 2010 [2].

Aim of this issue is to provide a comprehensive and upto-date overview about established laser techniques such as stone fragmentation, being modernized by modifications in laser performance and also to compare the different lasers introduced for soft tissue surgery and put the published techniques to a test.

The issue is opened by Jens Rassweiler from Heilbronn, Chairman of EAU Section of Uro-Technology (ESUT), giving an introduction on the topic and pointing out on the necessity to take care of the subject [3].

Kronenberg and Traxer present an outstanding review on Ho:YAG laser settings and fibres used for stone fragmentation. Although this procedure is carried out thousands of 
times each year and most users would say that the use of a Ho:YAG laser is common knowledge, the authors present an insight into the topic, which is hard to find in any other publication. The whole variety of technical factors, such as fibre diameter of frequency and pulse energy setting, is covered, allowing the reader to perform Ho:YAG lithotripsy on a new level [4].

This clinical overview is flanked by the publications of Bader et al. [5] and from the same group Skroka et al. [6], showing in vivo data, evaluation the effect of laser pulse duration on fibre burn and stone pushback, indication advantages for longer pulse durations in terms of convenient fragmentation.

Switching to laser surgery of the prostate in patients with LUTS due to BPO, we are very happy that Vincent and Gilling included an excellent review on Holmium laser Enucleation of the prostate (HoLEP) [7]. HoLEP, being the grandmother of all following transurethral enucleation procedures, being introduced more than 15 years ago in 1998, has come to age, evolving from a promising approach to an intensively studied surgical procedure, with proven long-term efficacy and reduced complications as compared to TUR-P and open prostatectomy. Conclusions are supported by an editorial letter from Ahyai, who considers HoLEP ready to fly [8].

However, although it was introduced almost a decade ago, learning curve of HoLEP, as well as of all other enucleation procedures, still is under discussion. As mentioned by Sugiono in 2007, "Gone are the days of a surgeon seeing a new technique and performing it the next day. Instead, mentorships and modular learning have been shown to ensure patient safety while allowing a surgeon to reach competency at a faster rate" [9].

This is why it is necessary to focus and to unite in our efforts to support new surgeons to establish transurethral enucleation programs. In an optimal scenario, the novel surgeon will have an expert at home, passing through his or her learning curve smoothly, as proven by Netsch et al. [10] working with the ThuVEP-group of Andreas Gross from Hamburg. However, there must be a way to implement transurethral enucleation in novel departments. Aho and Herrmann [11] recommend a striking overview on a modular mentorship programme, running in the UK since 2010, giving clear definitions on what you need to be considered as a mentor at first hand and proposing a stepwise approach throughout this program.

A newer approach for transurethral resection and enucleation of the prostate utilizes the Thulium:YAG laser. In 2010, an international group of users (Thulium Laser Working Group) evaluated and reflected in a consensus statement the development and early clinical results of this laser type [12], building on the first publication of 70-Watt Tm:YAG use in the prostate from 2007 [13]. Now, Xia and his co-workers, who reported their follow-up data on the
Thulium laser operation in 2014 [14, 15], contributed the first metaanalysis of nine RCTs on Tm:YAG vaporesection of the prostate (ThuVARP) [16].

What started 2009 with the first publication in the World Journal of Urology as Tm:YAG enucleation (ThuVEP) is now a matured, worldwide accepted technique [17]. A summarizing review on ThuVEP has been contributed by the working group around Andreas Gross from Hamburg, Germany, who introduced the technique to a review on current data on ThuVEP to this issue, including 14 peer-reviewed articles since 2009 including mid-term follow-up [18]. For another enucleation technique (ThuLEP) [19], utilizing the Thulium:YAG laser for coagulation and incision, while the actual enucleation is performed bluntly as proposed by Herrmann et al. also in the World Journal of Urology actual developments are summarized by Kyriazis et al. [20].

Besides enucleation techniques using the Holmium and thulium laser, photoselective vaporization of the prostate using the Greenlight laser has changed its performance significantly with rising power output of the laser source. Rieken and Bachmann [21] from Basel sum up the knowledge on the various systems and power settings in the sight of the "Goliath data".

In the light of expanding limits to the different laser systems and the implementation of transurethral enucleation as real alternative for all prostate sizes, Gomez Sancha et al. [22] are displaying how the Greenlight "vaporization tool" can be used for efficient enucleation of the prostate, following the trend away from open surgery to endourology.

Back to vaporization, Robert et al. [23] discuss the potential of bipolar vaporization systems, probably ready to challenge the Greenlight laser as first choice energy source for vaporization.

Even though lasers in urology have been a hot issue during the last 10 years, still new topics arise to focus on. Technical amendments and alterations have turned this tool into a treatment option for BPO. The current data are summed up by Lusardi, contributing a review to the recent data on diode laser treatment of BPO [24]. Other solutions, like laparoscopic or robot-assisted treatment pathways are reviewed by Lucca et al. [25] from Vienna in a systematic review of the published literature, giving the reader an interesting insight, in what is possible today and may widen the borders for laparoscopic surgery in the future.

Kramer and Herrmann from Hannover, who are one of the driving forces in laser en-bloc resection of bladder tumours, have put up an interesting review of the evidence for Tm: and Ho:YAG resection of bladder cancer, [26] building up on his previously published review on HF-techniques [27]. The future perspective of en-bloc resection is discussed by Karl and Herrmann in a letter to the editor, opening the discussion, if en-bloc enucleation may have the potential to replace TUR-B in the future [28]. 
The issue is concluded by laser treatment of the upper urinary tract. Emiliani and Breda [29] from Barcelona review the contemporary position of lasers in treating ureteral and UPJ-obstruction, while Liatsikos and co-workers discuss the future perspectives of partial nephrectomy with laser use [30]. Finally Emiliani et al. [31] discuss whether Tm:YAG could be the more appropriate tool for the treatment of upper urinary tract transitional cell carcinoma (UTUC).

Overall, the following issue presents a state-of-the-art overview on laser applications in urology. International experts are discussing the future directions and visions connected to this energy source, opening new horizons towards future applications.

\section{References}

1. Herrmann TR, Gross AJ (2007) Lasers in urology. World J Urol 25(3):215-216

2. Herrmann TR, Gross AJ (2010) Lasers for every organ. World J Urol 28(2):133

3. Rassweiler J (2015) T. R. W. Herrmann and T. Bach (eds.): Editorial comment on "What is relevant for lasers in urology?". World J Urol. doi:10.1007/s00345-015-1499-2

4. Kronenberg P, Traxer O (2014) Update on lasers in urology, current assessment on holmium:yttrium-aluminum-garnet (Ho:YAG) laser lithotripter settings and laser fibers. World J Urol. doi:10.1007/s00345-014-1395-1

5. Bader MJ, Pongratz T, Khoder W, Stief CG, Herrmann T, Nagele U, Sroka R (2015) Impact of pulse duration on Ho:YAG laser lithotripsy-fragmentation and dusting performance. World $\mathrm{J}$ Urol. doi:10.1007/s00345-014-1429-8

6. Sroka R, Pongratz T, Scheib G, Khoder W, Stief CG, Herrmann T, Nagele U, Bader MJ (2015) Impact of pulse duration on Ho:YAG laser lithotripsy: treatment aspects on the single-pulse level. World J Urol. doi:10.1007/s00345-015-1504-9

7. Vincent MW, Gilling PJ (2014) HoLEP has come of age. World J Urol. doi:10.1007/s00345-014-1443-x

8. Ahyai SA (2015) Re: World J Urol. 2014 Nov 22. [Epub ahead of print]. HoLEP has come of age. Vincent MW, Gilling PJ. World J Urol. doi:10.1007/s00345-015-1518-3

9. Sugiono M, Teber D, Anghel G, Gözen AS, Stock C, Hruza M, Frede T, Klein J, Rassweiler JJ (2007) Assessing the predictive validity and efficacy of a multimodal training programme for laparoscopic radical prostatectomy (LRP). Eur Urol 51(5):1332-1339

10. Netsch C, Bach T, Herrmann TR, Neubauer O, Gross AJ (2013) Evaluation of the learning curve for Thulium VapoEnucleation of the prostate (ThuVEP) using a mentor-based approach. World J Urol 31(5):1231-1238

11. Aho T, Herrmann TR (2014) Description of a modular mentorship programme for holmium laser enucleation of the prostate. World J Urol. doi:10.1007/s00345-014-1407-1

12. Bach T, Xia SJ, Yang Y, Mattioli S, Watson GM, Gross AJ, Herrmann TR (2010) Thulium: YAG $2 \mu \mathrm{m} \mathrm{cw}$ laser prostatectomy: where do we stand? World J Urol 28(2):163-168

13. Bach T, Herrmann TR, Ganzer R, Burchardt M, Gross AJ (2007) RevoLix vaporesection of the prostate: initial results of 54 patients with a 1-year follow-up. World J Urol 25(3):257-262
14. Cui D, Sun F, Zhuo J, Sun X, Han B, Zhao F, Jing Y, Lu J, Xia S (2014) A randomized trial comparing thulium laser resection to standard transurethral resection of the prostate for symptomatic benign prostatic hyperplasia: four-year follow-up results. World J Urol 32(3):683-689

15. Sun F, Han B, Cui D, Zhao F, Sun X, Zhuo J, Jing Y, Liu H, Xia S, Yang Y, Luo G, Guo F (2014) Long-term results of thulium laser resection of the prostate: a prospective study at multiple centers. World J Urol. doi:10.1007/s00345-014-1456-5

16. Zhu Y, Zhuo J, Xu D, Xia S, Herrmann TR (2014) Thulium laser versus standard transurethral resection of the prostate for benign prostatic obstruction: a systematic review and meta-analysis. World J Urol. doi:10.1007/s00345-014-1410-6

17. Bach T, Wendt-Nordahl G, Michel MS, Herrmann TR, Gross AJ (2009) Feasibility and efficacy of Thulium:YAG laser enucleation (VapoEnucleation) of the prostate. World J Urol 27(4):541-545

18. Netsch C, Bach T, Herrmann TR, Gross AJ (2014) Update on the current evidence for Tm:YAG vapoenucleation of the prostate 2014. World J Urol. doi:10.1007/s00345-014-1417-z

19. Herrmann TR, Bach T, Imkamp F, Georgiou A, Burchardt M, Oelke M, Gross AJ (2010) Thulium laser enucleation of the prostate (ThuLEP): transurethral anatomical prostatectomy with laser support. Introduction of a novel technique for the treatment of benign prostatic obstruction. World J Urol 28(1):45-51

20. Kyriazis I, Świniarski PP, Jutzi S, Wolters M, Netsch C, Burchardt M, Liatsikos E, Xia S, Bach T, Gross AJ, Herrmann TR (2014) Update on transurethral anatomical enucleation of the prostate with Tm:YAG support (ThuLEP). World J Urol. doi:10.1007/s00345-015-1529-0

21. Rieken M, Bachmann A (2014) Update on Greenlight laser vaporization (PVP) 2014. World J Urol. doi:10.1007/ s00345-014-1437-8

22. Gomez Sancha F, Rivera VC, Georgiev G, Botsevski A, Kotsev J, Herrmann T (2014) Common trend: move to enucleation-is there a case for GreenLight enucleation? Development and description of the technique. World J Urol. doi:10.1007/ s00345-014-1339-9

23. Robert G, De la Taille A, Herrmann T (2014) Bipolar plasma vaporization of the prostate: Ready to replace GreenLight? A systematic review of randomized controlled trials. World J Urol. doi:10.1007/s00345-014-1384-4

24. Lusardi L, Mitterberger M, Hruby S, Kunit T, Kloss B, Engelhardt PF, Sieberer M, Janetschek G (2014) Update on the use of diode laser in the management of benign prostate obstruction in 2014. World J Urol. doi:10.1007/s00345-014-1327-0

25. Lucca I, Shariat S, Hofbauer S, Klatte T (2014) Outcomes of minimally invasive simple prostatectomy for benign hyperplasia: a systematic review and meta-analysis. World J Urol. doi:10.1007/s00345-014-1324-3)

26. Kramer MW, Wolters M, Cash H, Jutzi S, Imkamp F, Kuczyk MA, Merseburger AS, Herrmann TRW (2014) Current evidence of transurethral Ho:YAG and Tm:YAG treatment of bladder cancer: update 2014. World J Urol. doi:10.1007/s00345-014-1337-y

27. Kramer MW, Abdelkawi IF, Wolters M, Bach T, Gross AJ, Nagele U, Conort P, Merseburger AS, Kuczyk MA, Herrmann TR (2014) Current evidence for transurethral en bloc resection of non-muscle-invasive bladder cancer. Minim Invasive Ther Allied Technol 23(4):206-213. doi:10.3109/13645706.2014.880065

28. Karl A, Herrmann TR (2015) En bloc resection of urothelial cancer within the urinary bladder: the upcoming gold standard? World J Urol. doi:10.1007/s00345-015-1498-3

29. Emiliani E, Breda A (2014) Laser endoureterotomy and endopyelotomy: an update. World J Urol. doi:10.1007/ s00345-014-1405-3 
30. Kyriazis I, Ozsoy M, Kallidonis P, Panagopoulos V, Marinos V, Liatsikos E (2014) Current evidence on lasers in laparoscopy: partial nephrectomy. World J Urol. doi:10.1007/ s00345-014-1343-0
31. Emiliani E, Herrmann TR, Breda A (2015) Thulium laser for the treatment of upper urinary tract carcinoma (UTUC)? Are we there, yet? World J Urol. doi:10.1007/s00345-015-1511-x 